\title{
Optimasi Desain Kursi Menggunakan Metode Elemen Hingga
}

\author{
Sakuri Dahlan ${ }^{\text {a }}$, Reza Azizul Nasa Al Hakim ${ }^{\text {b, } *}$ \\ ${ }^{a}$ Dosen Program Studi S1 Jurusan Teknik Mesin, Sekolah Tinggi Teknik Wiworotomo \\ Jl. Semingkir No. 1 Purwokerto Barat 53134, Telp +62281632870 \\ ${ }^{\mathrm{b}}$ Mahasiswa Program Studi S2 Departemen Teknik Mesin, Fakultas Teknik, Universitas Diponegoro \\ JL. Prof Sudharto, SH., Tembalang-Semarang 50275, Telp +62247460059 \\ *E-mail: rezaazizul@gmail.com
}

\begin{abstract}
Chairs are a tool that we always meet in our activities every day. Every day we will find seats even we will always use the chairs to perform daily activities. The average person uses chairs approximately 2 3 hours per day. In the community there are many kinds of chairs ranging from wooden chairs, plastic chairs, folding chairs, and others. Most people tend to prefer to use plastic chairs. In addition to easy to move, plastic seats also have a cheaper price than the other seats. Plastic chairs are often found in food stalls in Indonesia. There are various designs and forms of plastic chairs that are sold in the community. In one of the existing plastic chair models in the community will be optimized to obtain optimal results, so as to minimize the weight of the seat but the strength and endurance of the seat remains the same. The result obtained is the obtained mass decreases from $1.4 \mathrm{~kg}$ to $0.94 \mathrm{~kg}$. Thus the plastic seats have been optimized mass of $0.46 \mathrm{~kg}$.
\end{abstract}

Keywords: Plastic seats; mass; optimization

\section{Abstrak}

Kursi merupakan suatu alat bantu yang selalu kita jumpai di aktivitas kita sekari-hari. Setiap hari kita akan menjumpai kursi bahkan kita akan selalu menggunakan kursi untuk melakukan kegiatan seharihari. Rata-rata orang menggunakan kursi kurang lebih 2-3 jam perhari. Di masyarakat banyak dijumpai berbagai macam jenis kursi mulai dari kursi kayu, kursi plastik, kursi lipat, dan lain-lain. Sebagian besar masayarakat cenderung lebih senang menggunakan kursi plastik. Selain mudah untuk dipindahkan, kursi plastik juga memiliki harga yang lebih murah dibandingkan dengan kursi yang lainnya. Kursi plastik banyak dijumpai di warung makan yang ada di Indonesia. Ada berbagai macam desain dan bentuk kursi plastik yang dijual di masyarakat. Pada salah satu model kursi plastik yang ada di masyarakat akan dioptimasi untuk mendapatkan hasil yang optimal, sehingga bisa meminimalkan berat kursi tetapi kekuatan dan daya tahan kursi tetap sama. Hasil yang diperoleh adalah massa yang didapat berkurang dari $1.4 \mathrm{~kg}$ menjadi $0.94 \mathrm{~kg}$. Dengan demikian kursi plastik tersebut telah dioptimasi massanya sebesar $0.46 \mathrm{~kg}$.

Kata kunci: Kursi plastik; massa; optimasi

\section{Pendahuluan}

Pengertian kursi lipat (folding chair) adalah salah satu jenis kursi portabel, memiliki sistem lipatan datar, dan dapat disimpan. Kursi lipat biasanya digunakan di mana tempat duduk permanen tidak dapat dipasang atau tempat yang tidak memungkinkan. Hal ini termasuk acara indoor dan outdoor seperti kuliah, pelayanan keagamaan, dan permainan olahraga. Kursi lipat juga dapat digunakan untuk setiap keadaan yang membutuhkan tempat duduk ekstra [1].

Pada tahun 1947, Fredric Arnold menciptakan kursi lipat aluminium pertama kali dengan kain sebagai alas dan sandaran punggung. Pada tahun 1957, perusahaan Fredric Arnold di Brooklyn, New York memproduksi lebih dari 14.000 kursi per hari. Saat ini, kursi lipat sebagian besar terbuat dari plastik keras, alumunium, logam, dan kayu [2].

Kursi lipat dapat dibagi ke dalam beberapa kategori yang berbeda:

a. Desain

Kursi lipat biasanya memiliki berat antara 2 sampai $5 \mathrm{~kg}$ (5-10 pon) dan diproduksi dalam model, mekanisme lipat, dan komponen.

b. Kaki Pivoting

Kaki kursi lipat (pivot) untuk melipat biasanya berada di bawah kursi, atau di depan kursi. Kebanyakan pivot berada di tengah kursi. Dimensi sandaran punggung dan kaki sama. Namun, beberapa desain memiliki sistem lipat yang melipat di bawah kursi. Pivot $\mathrm{X}$ terdiri dari 2 potong plat berbentuk $\mathrm{X}$ dengan selembar kain diantara rangka alas yang menjadi alas duduk dengan penambahan sandaran. 

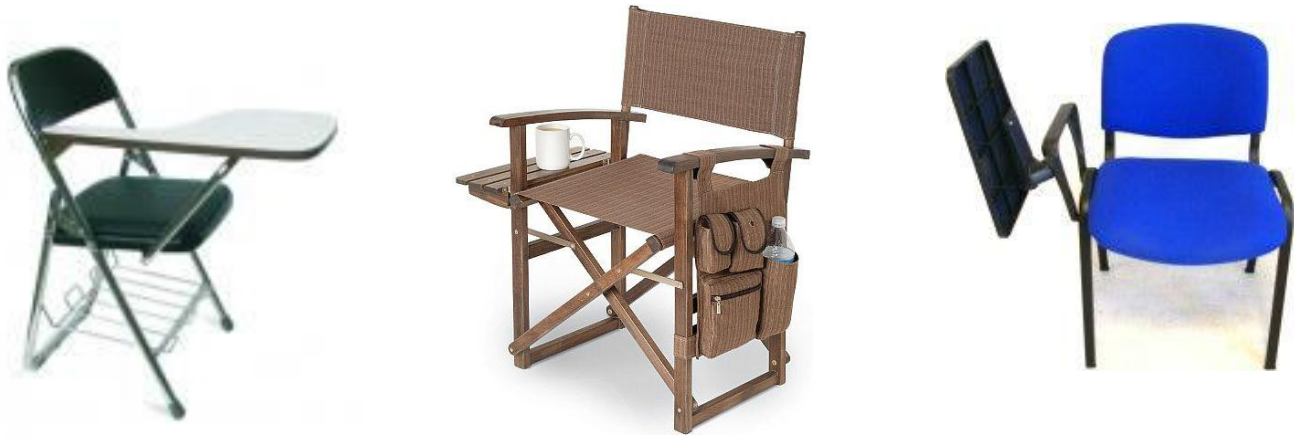

Gambar 1. Jenis - jenis rangka kursi [3]

Manusia adalah makhluk yang paling sukses berevolusi di Bumi, salah satu dampak terbesar dari proses evolusi tersebut adalah kemampuan manusia untuk berjalan dengan tegak dengan menggunakan kedua kaki [4]. Tujuan dari fasilitas kursi adalah menyangga tubuh manusia sehingga kestabilan postur tubuh dapat terjaga dengan baik. Dengan demikian, didapatkan rasa nyaman untuk beberapa waktu dan secara psikis merasakan kepuasan [5]. Ergonomi berasal dari bahasa latin yaitu Ergon (kerja) dan Nomos (hukum alam) dan dapat didefinisikan sebagai study tentang aspekaspek manusia dalam lingkungan kerjanya yang ditinjau secara anatomi, fisiologi, psikologi, engineering, management dan perancangan [6].Dapat dilihat pada Gambar 2 merupakan hal-hal yang perlu diperhatian dalam menentukan desain kursi kuliah.

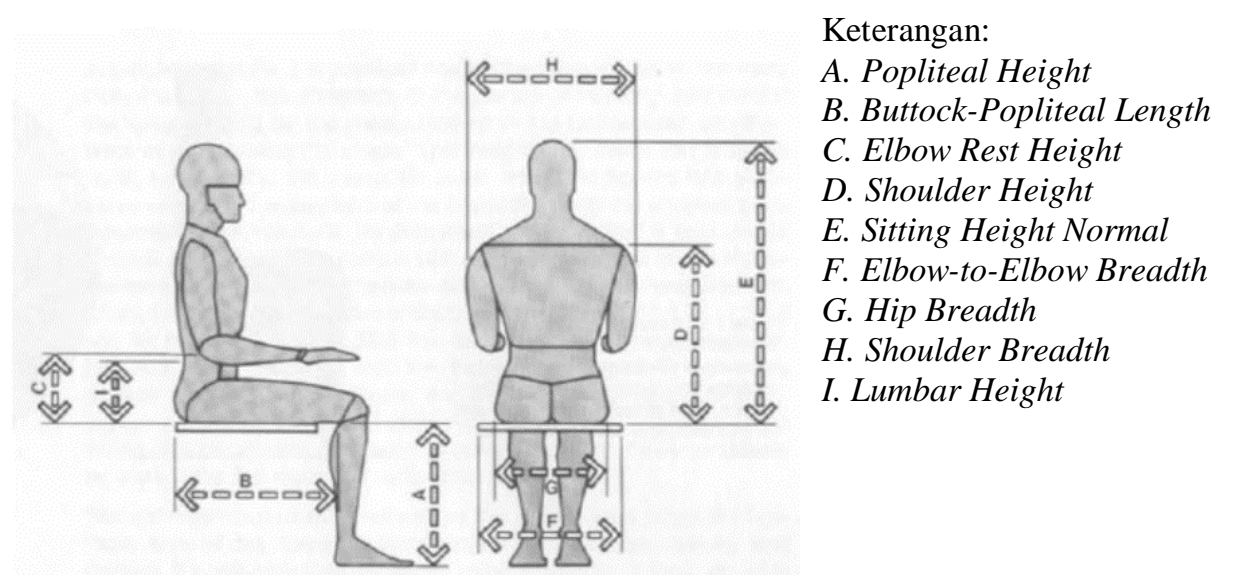

Gambar 2. Anthropometri yang digunakan untuk redesain kursi kuliah [1]

Posisi duduk yang benar berdasarkan Ergonomi adalah [7]:

1. Duduk dengan punggung lurus dan bahu berada di belakang serta pantat menyentuh belakang kursi. Seluruh lengkung tulang belakang harus terdapat selama duduk.

2. Duduklah dengan lutut tetap setinggi atau sedikit lebih tinggi panggul (gunakan penyangga kaki bila perlu).

3. Paha dalam posisi horizontal dan punggung bagian bawah atau pinggang terdukung.

4. Kedua tungkai tidak saling menyilang.

5. Jaga agar kedua kaki tidak menggantung.

6. Telapak kaki harus dapat menumpu secara rata di lantai ketika duduk. Apabila tidak menggunakan penyangga kaki.

7. Hindari duduk dengan posisi yang sama lebih dari 20-30 menit.

8. Selama duduk, istirahatkan siku dan lengan pada kursi, bahu tetap rileks

9. Bila duduk dengan kursi beroda dan berputar, jangan memutarkan pinggang selama duduk, sebaiknya putarkan seluruh tubuh.

Tujuan penelitian ini adalah mengoptimasi massa dari kursi plastik menggunakan metode optimasi desain. Metode yang digunakan pada penelitian menggunakan Finite Element Method (FEM). Pemodelan kursi menggunakan Solidworks kemudian dianalisis menggunakan metode FEM.

\section{Material dan Metode Penelitian}

\subsection{Material Model}

Terdapat berbagai macam jenis material kayu yang digunakan untuk membuat kursi, namun untuk pemodelan material kayu yang digunakan adalah kayu jenis Balsa dengan material properties seperti di bawah ini : 
Tabel 1. Sifat mekanis PVC

\begin{tabular}{cc}
\hline Tabel 1. Sifat mekanis PVC & Nilai \\
\hline Sifat Mekanis & 1.305 \\
Density $(g / c c)$ & 47 \\
Ultimate Tensile Strength $(\mathrm{MPa})$ & 38 \\
Yield Strength $(\mathrm{MPa})$ & 3.1 \\
Flexural Modulus $(\mathrm{GPa})$ & \\
\hline
\end{tabular}

\subsection{Geometri Model}

Geometri yang digunakan pada penelitian ini adalah jenis kursi plastik yang biasa digunakan sehari hari. Untuk detail dari dimensi dapat dilihat pada Tabel 2.

Tabel 2. Dimensi kursi

\begin{tabular}{cc}
\hline Sifat Mekanis & Nilai \\
\hline Tinggi $(\mathrm{cm})$ & 40 \\
Lebar $(\mathrm{cm})$ & 45 \\
Tebal $(\mathrm{cm})$ & 1 \\
Massa $(\mathrm{Kg})$ & 1.4 \\
\hline
\end{tabular}

Untuk desain kursi dapat dilihat pada Gambar 3(a) dan Gambar meshing pada Gambar 3(b)

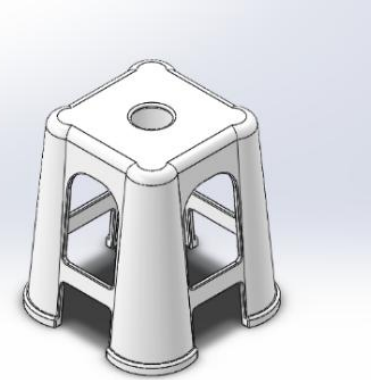

(a)

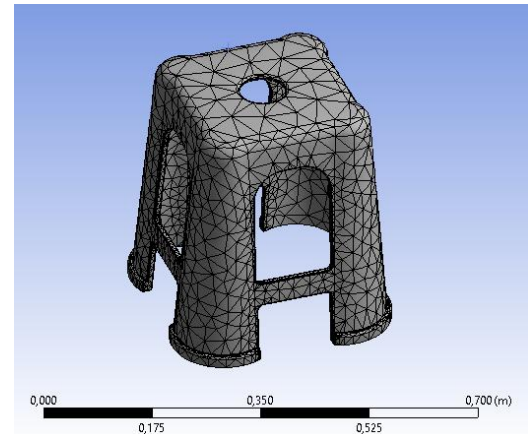

(b)

Gambar 3. (a) Desain kursi, (b) Hasil Meshing pada kursi

Jenis meshing yang digunakan untuk analisis kursi ini adalah tetrahedral. Pemilihan jenis mesh ini karena mesh jenis tetrahedral memiliki kemampuan yang lebih baik untuk diterapkan pada geometri kursi ini [8]. Dari proses mesh yang dilakukan, terdapat jumlah nodal sebesar 30749 dan element sebesar 16056. Hasil dari proses meshing dapat dilihat pada Gambar 4.

\subsection{Kondisi Batas}

Nilai dari beban yang akan di aplikasikan pada model menggunakan nilai dari penelitian yang telah dilakukan oleh Edy Wiranata[9]. Beban sebesar $1500 \mathrm{~N}$ di aplikasikan searah pada bagian alas bagian atas kursi. Bagian bawah kursi (kaki-kaki kursi) diberikan tumpuan jepit. Untuk lebih jelasnya dapat dilihat pada Gambar 4.

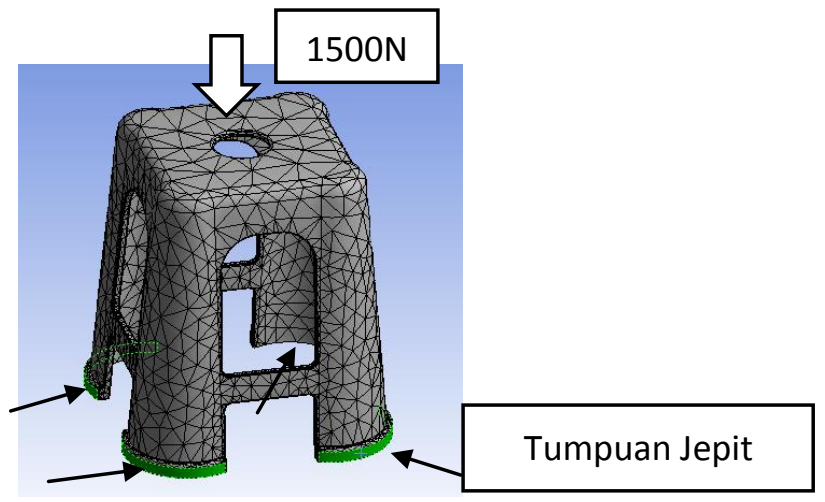

Gambar 4. Kondisi batas yang diberikan pada analisi kursi 


\section{c. Hasil dan Pembahasan}

Dari hasil analisis metode elemen hingga, Gambar 5 menunjukkan hasil distribusi dari tegangan yang terjadi akibat pembebanan yang diberikan kepada kursi. Tegangan yang terjadi pada bagian tengan kursi berkisar $1.1622 \mathrm{e} 7 \mathrm{~Pa}$ (11.622 MPa). Untuk hasil simulasi dapat dilihat pada Gambar 5.

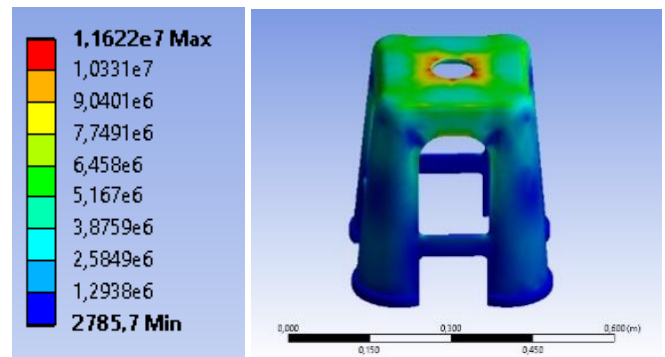

Gambar 5. Distribusi tegangan yang terjadi akibat pembebanan pada kursi.

Gambar 6 menunjukkan deformasi total yang terjadi akibat pembebanan. Terlihat bahwa terjadi deformasi terbesar yaitu $0.9457 \mathrm{~mm}$ pada bagian alas kursi.
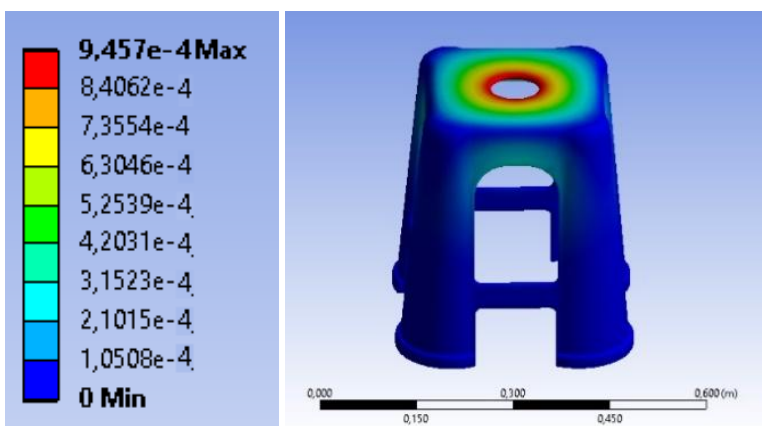

Gambar 6. Deformasi yang terjadi akibat pembebanan pada kursi

Pada Gambar 7 menunjukkan safety factor yang terjadi pada kursi. Secara keseluruhan, terdapat nilai safety factor yaitu 4.852. Nilai safety factor yang terjadi masih cukup besar, nilai safety factor minimum yang ditetapkan sebesar 2[9]. Karena nilai safety factor yang masih lebih tinggi dibandingkan yang ditetapkan, maka akan dilakukan optimasi pada kursi.

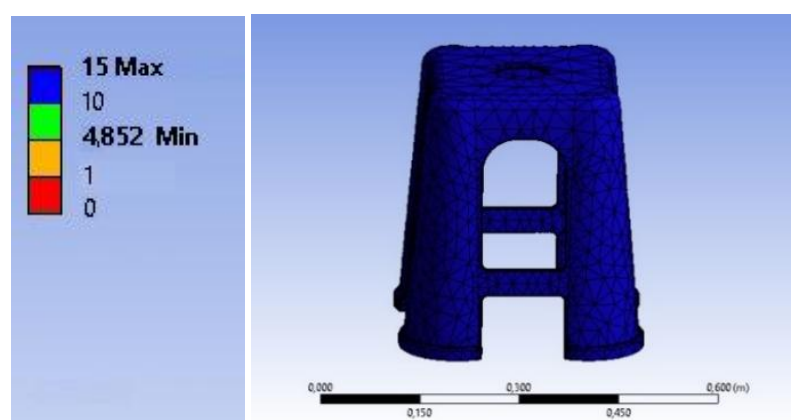

Gambar 7. Nilai safety factor yang terjadi pada kursi

Proses optimasi adalah sebuah proses yang dilakukan untuk dapat menghasilkan suatu hasil yang terbaik pada kondisi yang telah ditentukan. Dalam desai, konstruksi, dan maintenance engineering, proses optimasi sangat berperan penting. Tujuan utama dari proses ini adalah untuk meminimalkan usaha yang diperlukan ataupun memaksimalkan potensi dari sebuah sistem [10].

Kursi yang telah dilakukan analisis menggunakan metode elemen hingga masih menunjukkan kesempatan untuk dilakukan proses optimasi. Nilai safety factor yang terjadi masih dapat dikurangi dengan mengubah ketebalan dari material yang digunakan. Tentunya hal ini akan berimbas pada pengurangan massa total kursi. Pada Tabel 3 merupakan objective function dari proses optimasi yang dilakukan.

Tabel 3. Objective function

\begin{tabular}{cc}
\hline Objective Function & Status \\
\hline Safety Factor & $2<\mathrm{x}<4$ \\
Massa $($ Kg) & Minimal \\
\hline
\end{tabular}


Untuk mencapai objective function yang telah ditentukan, maka diperlukan perubahan pada bagian desain. Tabel 4 menunjukkan desain variabel yang digunakan dalam proses optimasi.

Tabel 4. Desain Variabel

\begin{tabular}{ccc}
\hline \multirow{2}{*}{ Bagian } & \multicolumn{2}{c}{ Ketebalan } \\
\cline { 2 - 3 } & Batas bawah & Batas Atas \\
\hline Kursi & $0.5 \mathrm{~mm}$ & $1 \mathrm{~mm}$ \\
Kaki Kursi & $0.5 \mathrm{~mm}$ & $1 \mathrm{~mm}$ \\
\hline
\end{tabular}

Dari proses optimasi yang dilakukan, terdapat 2 pilihan hasil yang disarankan dalam perubahan desain yang akan dilakukan. Tabel 5 menunjukkan pilihan - pilihan terbaik yang didasarkan dari objective function serta desain variabel yang digunakan. Opsi kedua menunjukkan opsi terbaik dari beberapa opsi yang telah dilakukan.

Tabel 5. Hasil proses optimasi

\begin{tabular}{ccc}
\hline Bagian & Opsi 1 & Opsi 2 \\
\hline Kursi & $0.67 \mathrm{~mm}$ & $0.7 \mathrm{~mm}$ \\
Kaki Kursi & $0.95 \mathrm{~mm}$ & $1 \mathrm{~mm}$ \\
Massa & $0.93 \mathrm{~kg}$ & $0.94 \mathrm{~kg}$ \\
Safety Factor & 3.14 & 3.22 \\
\hline
\end{tabular}

Proses optimasi menunjukkan bahwa kursi yang telah dioptimasi menunjukkan perubahan pada ketebalan desain awal kursi. Pada desain utama mengalami perubahan menjadi $0.7 \mathrm{~mm}$ dan pada kaki kursi menjadi $1 \mathrm{~mm}$ dan menghasilkan penurunan massa menjadi $0.94 \mathrm{~kg}$ dengan nilai safety factor sebesar 3.22.

\section{Kesimpulan}

Hasil perancangan kursi telah melalui proses analisis menggunakan metode elemen hingga dimana dari pembebanan yang telah dilakukan mengahasilkan tegangan maksimum sebesar $11.622 \mathrm{MPa}$ dengan nilai safety factor 4.8353. Proses optimasi yang dilakukan pada kursi mampu mengurangi massa dari kursi yang semula $1.4 \mathrm{~kg}$ menjadi $0.94 \mathrm{~kg}$ dengan nilai safety factor berada pada 3.22. Dengan proses optimasi yang dilakukan, kursi dapat dibuat dengan berat yang minimal tetapi tidak berpengaruh terhadap kekuatan serta ketahanan kursi itu sendiri karena safety factor dari hasil optimasi masih berada diatas nilai safety factor yang direkomendasikan untuk pembuatan kursi.

\section{Daftar Pustaka}

[1] Panero, J., 1979. Dimensi Manusia \& Ruang Interior. Erlangga.

[2] Wignjosoebroto, S., 1995. Ergonomi. Study Gerak dan Waktu, 1st Ed., Guna Widya, Jakarta, pp.65-66.

[3] www.directourchair.com (Diakses tanggal 2 juli 2018)

[4] Klein, D.F., 1999. Harmful dysfunction, disorder, disease, illness, and evolution, Journal of Abnormal Psychology, 108(3), 421-429.

[5] Pheasant, S., 1987. Some anthropometric aspects of workstation design. International journal of nursing studies, 24(4), pp.291-298.

[6] Nurmianto, E., 2004. Ergonomi. Konsep Dasar dan Aplikasinya, Guna Widya, Surabaya.

[7] Samara, D., Basuki, B., Jannis, J., 2005. Duduk statis sebagai faktor risiko terjadinya nyeri punggung bawah pada pekerja perempuan. Universa Medicina, 24(2), pp.73-79.

[8] Jo Y. W., Robert L., 1997. The advantages of triangular and tetrahedral edge elements for electromagnetic modeling with the finite-element method, IEEE Trans. Antennas Propag., vol. 45, no. 9, pp. 1431-1437.

[9] Wiranata, E., 2011. Redesain Kursi Kuliah Ergonomis dengan Pendekatan Anthropometri (Doctoral dissertation, Universitas Sebelas Maret).

[10] Singiresu S. R., 2009. Engineering Optimization: Theory and Practice. 